\title{
HUBUNGAN NYERI TENGGOROK DAN FAKTOR RISIKO PASIEN PASCA OPERASI DENGAN ANESTESI UMUM INTUBASI ENDOTRAKEAL DI PPK BLUD RSU CUT MEUTIA ACEH UTARA
}

\author{
Anna Millizia $^{1}$, Fury Maulina ${ }^{1}$, Tan Wily Ramadhani ${ }^{2}$ \\ ${ }^{1}$ Program Studi Kedokteran, Fakultas Kedokteran, Universitas Malikussaleh \\ 2 Bagian Ilmu Anestesiologi, Fakutas Kedokteran, Universitas Malikussaleh \\ Corresponding Author : annamillizia@gmail.com
}

\begin{abstract}
Abstrak
Nyeri tenggorok adalah komplikasi umum yang terjadi pasca operasi dengan anestesi umum intubasi endotrakeal. Nyeri tenggorok dikaitkan dengan beberapa faktor risiko pasien pasca operasi dengan anestesi umum intubasi endotrakeal seperti usia, jenis kelamin, riwayat merokok, durasi intubasi dan ukuran pipa endotrakeal. Penelitian ini bertujuan untuk mengetahui hubungan nyeri tenggorok dan faktor risiko pasien pasca operasi dengan anestesi umum intubasi endotrakeal di PPK BLUD RSU Cut Meutia Aceh Utara. Penelitian ini menggunakan pendekatan cross sectional yang diadakan pada 41 pasien yang mengalami nyeri tenggorok pasca operasi dengan anestesi umum intubasi pada April-Mei 2018, dengan menggunakan uji Pearson Chi-square. Distribusi frekuensi nyeri tenggorok derajat sedang dalam 24 jam Pasca operasi adalah 61\%, usia 18-60 tahun yaitu $95,1 \%$, jenis kelamin laki-laki yaitu $63,4 \%$, perokok yaitu $56,1 \%$, durasi itubasi $>60$ menit yaitu 56,1\% dan yang sering digunakan adalah ukuran pipa endotrakeal 7,0 ID. Berdasarkan uji Pearson Chi-Square, didapatkan bahwa nyeri tenggorok tidak berhubungan dengan usia, jenis kelamin serta terdapat hubungan nyeri tenggorok dan riwayat merokok $(p=0,004)$; durasi intubasi $(p=0,011)$ dan ukuran pipa endotrakeal $(\mathrm{p}=0,002)$ pasien pasca operasi dengan anestesi umum intubasi endotrakeal di PPK BLUD RSU Cut Meutia Aceh Utara. Kesimpulannya adalah terdapat hubungan nyeri tenggorok dan riwayat merokok, durasi intubasi serta ukuran pipa endotrakeal pasien pasca operasi dengan anestesi umum intubasi endotrakeal di PPK BLUD RSU Cut Meutia Aceh Utara.
\end{abstract}

Kata Kunci :anestesi umum; faktor risiko; intubasi endotrakeal; nyeri tenggorok

Jurnal Averrous Vol.4 No.2 2018 


\title{
The Associaton Between Postoperative Sore Throat and Risk Factors in General Anesthesia of Endotracheal Intubation in General Hospital in North Aceh
}

\begin{abstract}
Sore throat is a common postoperative complication in general anesthesia of endotracheal intubation. Sore throat is related to several factors such as age, sex, smoking, duration of intubation and size of endotracheal tube. This research aimed to identify the association between postoperative sore throat and risk factors in general anesthesia of endotracheal intubation in General Hospital in North Aceh. This study used cross sectional survey which conducted for 41 patients who had postoperative sore throat in general anesthesia intubation on April-May 2018, with Pearson Chi- square test. The results showed that moderate sore throat was dominant (61\%) . aged 18-60 were

$95,1 \%$, male were $63,4 \%$. $56,1 \%$ were smoker, duration of intubation $>60$ minutes were $56,1 \%$,

while size of endotracheal tube 7.0 ID were dominants. There were no association between postoperative sore throat with aged and sex and there were association between postoperative so re throat with smokers $(p=0,004)$; duration of intubation $(p=0,011)$ and size of endotracheal tube $(p=0,002)$. We concluded that there were association between postoperative sore throat with smokers, duration of intubation and size of endotracheal tube in general anesthesia of endotracheal intubation in General Hospital in North Aceh.
\end{abstract}

Keywords: general anesthesia; risk factors; endotracheal intubation; sore throat 


\section{PENDAHULUAN}

Nyeri tenggorok adalah komplikasi umum yang terjadi pasca operasi dengan anestesi umum intubasi endotrakeal (1). Komplikasi ini merupakan komplikasi ringan, bersifat sementara dan dapat sembuh sendiri dalam beberapa hari, namun kurang etis apabila penderita selain harus menahan nyeri akibat pembedahan, juga harus menerima penderitaan pada saluran nafas bagian atas dan merupakan efek samping yang sering dikeluhkan pasien periode pasca operasi (2).

Nyeri tenggorok pasca operasi dengan anestesi umum intubasi endotrakeal merupakan suatu keadaan yang masih menjadi persoalan utama (2). Nyeri tenggorok pasca operasi dengan anestesi umum intubasi endotrakeal adalah komplikasi paling umum yang dapat terjadi terhadap pasien dan menduduki peringkat ke-2 sebagai kejadian buruk minor selama pemulihan anestesi, meskipun ada kemajuan pesat dalam teknik anestesi (3). Nyeri tenggorok pasca operasi adalah keluhan terbesar ke-8 terhadap pasien yang menjalani anestesia umum (4).

Kejadian nyeri tenggorok bervariasi dalam kebanyakan penelitian, namun beberapa melaporkan insiden sekitar 15\% sampai 64\% (5). Angka kejadian nyeri tenggorok pasca operasi dengan anestesi umum intubasi endotrakeal adalah 6 sampai $76 \%$ (2). Insidensi nyeri tenggorok pasca operasi dengan anestesi intubasi endotrakeal bervariasi dari 14,4\% sampai 100\% (6). Berdasarkan penelitian Biro, Seifert dan Pasch, (2005) dalam Fahriyani, Irawan dan Bebasari (2014) menunjukkan bahwa $40 \%$ pasien (323 orang) mengeluhkan timbulnya nyeri tenggorok dari 809 pasien yang diintubasi. Insidensi nyeri tenggorok yang dilaporkan oleh Lev dan Rosen mempunyai insidensi sebesar 90\% (7).

Nyeri tenggorok pasca operasi dengan anestesi umum intubasi endotrakeal merupakan rasa tidak nyaman, nyeri, atau gatal di tenggorokan dan biasanya menimbulkan nyeri untuk menelan. Keluhan tersebut dapat hilang beberapa jam tetapi dapat juga sampai dua hari atau lebih (8). Nyeri tenggorok terjadi dalam 24 jam pertama pada pasien pasca operasi dengan anestesi umum intubasi endotrakeal (9). Nyeri tenggorok yang menimbulkan nyeri untuk menelan berlangsung 24 sampai 48 jam pada pasien pasca operasi dengan anestesi umum intubasi endotrakeal (10). Penyebab utama nyeri tenggorok pasca operasi dengan anestesi umum intubasi endotrakeal adalah trauma pada mukosa faringolaringeal karena tindakan laringoskopi dan pemasangan pipa endotrakeal sedangkan penyebab yang lain adalah pemasangan Nasogastric Tube (NGT) dan penyedotan lendir dalam mulut (7) (11).

Nyeri tenggorok pasca operasi dengan aestesi umum intubasi endotrakeal dapat terjadi karena berbagai faktor yaitu faktor pasien, faktor peralatan, dan teknik intubasi (12). Faktor risiko yang berperan dalam timbulnya keluhan nyeri tenggorok antara lain jenis kelamin, usia, riwayat merokok, durasi intubasi dan ukuran pipa endotrakeal (13)(14)(15). 


\section{METODE PENELITIAN \\ Desain penelitian}

Penelitian ini menggunakan jenis penelitian analitik observasional dengan pendekatan cross sectional. Lokasi yang dipilih untuk penelitian ini adalah PPK BLUD RSU Cut Meutia Aceh Utara.

\section{Populasi dan sampel penelitian}

Populasi dalam penelitian ini adalah seluruh pasien operasi dengan anestesi umum intubasi endotrakeal. Sampel dalam penelitian ini adalah pasien pasca operasi dengan anestesi umum intubasi endotrakeal pada periode penelitian memenuhi kritreria inklusi dan eksklusi.

Kriteria Inklusi :

1. Pasien yang menjalani intubasi orotrakeal.

2. Pasien berusia $\geq 18$ tahun.

3. Pasien status fisik ASA 1 atau 2.

4. Pasien yang bersedia menjadi responden.

Kriteria Eksklusi :

1. Pasien yang menjalani operasi di bagian rongga tenggorok.

2. Pasien dengan usaha intubasi lebih dari dua kali.

3. Pasien anestesi umum intubasi endotrakeal dengan ukuran pipa endotrakeal 8,0 .

4. Adanya riwayat nyeri tenggorok sebelum operasi pada pasien pasca operasi dengan anestesi umum intubasi endotrakeal.

\section{Teknik pengambilan sampel}

Sampel pada penelitian ini diambil dengan cara consecutive sampling. Berdasarkan perhitungan besar sampel dengan menggunakan rumus lameshow, maka besar sampel yang dibutuhkan seluruhnya adalah 31 pasien dan diambil sebanyak 42 pasien.

\section{Analisis data}

Analisis dan penyajian data yang dilakukan adalah sebagai berikut:

1. Analisis Univariat

Analisis univariat adalah analisis dalam bentuk tabel distribusi frekuensi untuk mendeskripsikan setiap faktor risiko nyeri tenggorok pasien pasca operasi dengan anestesi umum intubasi endotrakeal

2. Analisis Bivariat

Analisis bivariat dalam penelitian ini bertujuan untuk mengidentifikasi hubungan setiap variabel dalam penelitian ini dan nyeri tenggorok pasca operasi dengan anestesi umum intubasi endotrakeal menggunakan uji Chi Square. 


\section{HASIL PENELITIAN}

Distribusi Frekuensi Derajat Nyeri Tenggorok

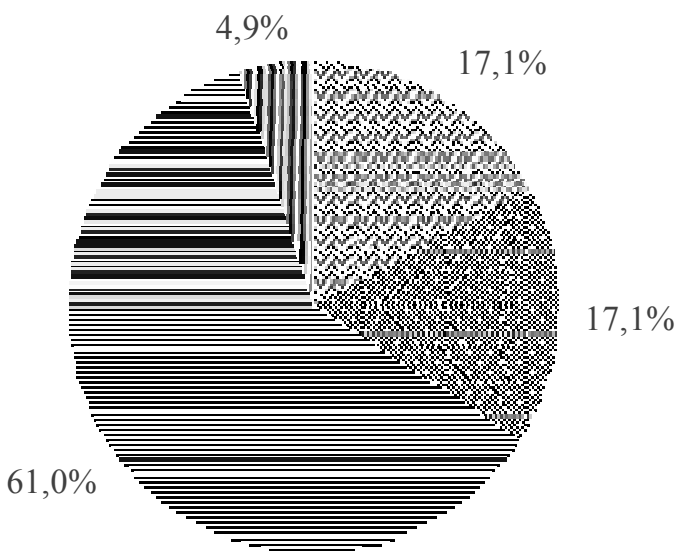

א' Tidak Nyeri $\quad$ Nyeri Ringan ENyeri Sedang IINyeri Berat

Gambar 5.1 Distribusi Frekuensi Derajat Nyeri Tenggorok

Gambar 5.1 menunjukkan bahwa pasien pasca operasi dengan anestesi umum intubasi endotrakeal sebagian besar mengeluh nyeri tenggorok sedang sebesar 61\% (25/41) dan sebesar 4,9\% (2/41) mengeluh nyeri tenggorok berat.

\section{Distribusi Frekuensi Faktor Risiko}

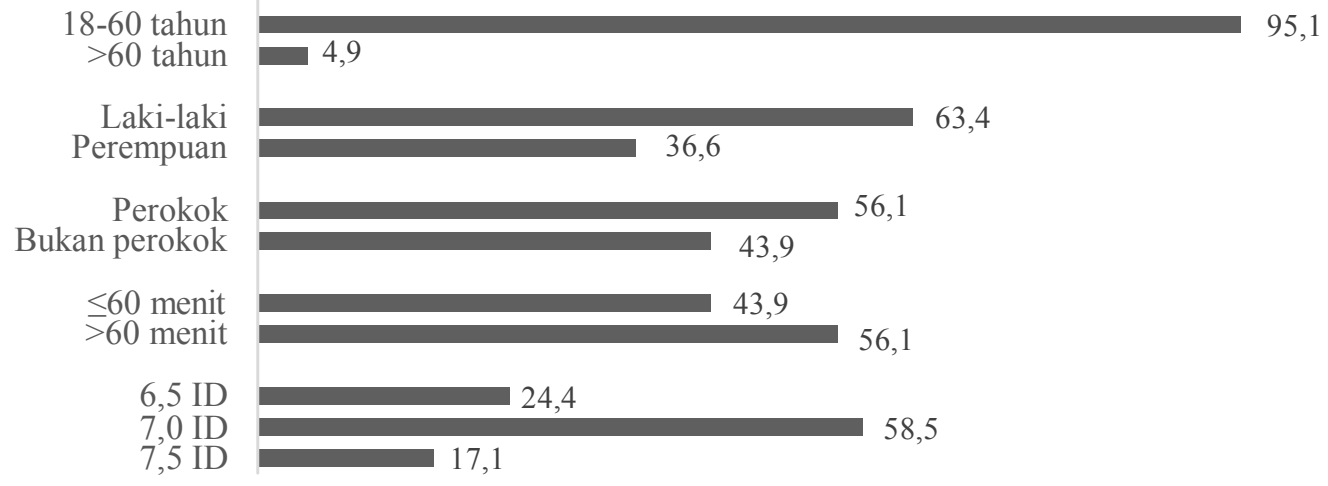

Jurnal Averrous Vol.4 No.2 2018 


\section{Gambar 5.2 Distribusi Frekuensi Faktor Risiko Pasien Pasca Operasi dengan}

Anestesi Umum Intubasi Endotrakeal (dalam persen)

Gambar 5.2 menunjukkan bahwa pasien pasca operasi dengan anestesi umum intubasi endotrakeal sebagian besar usia 18-60 tahun yaitu 95,1\% (39/41), didominasi oleh laki-laki sebesar 63,4\% (26/41) dan 56,1\% (23/41) adalah perokok. Durasi intubasi terbesar yaitu $>60$ menit sebesar 56,1\% (23/41), sedangkan ukuran pipa endotrakeal yang paling sering digunakan yaitu 7,0 ID sebesar 58,5\% (24/41). 
Tabel 5.1. Hubungan Nyeri Tenggorok dan Faktor Risiko Pasien Pasca Opeasi dengan Anestesi Umum Intubasi Endotrakeal di PPK BLUD RSU Cut Meutia Aceh Utara

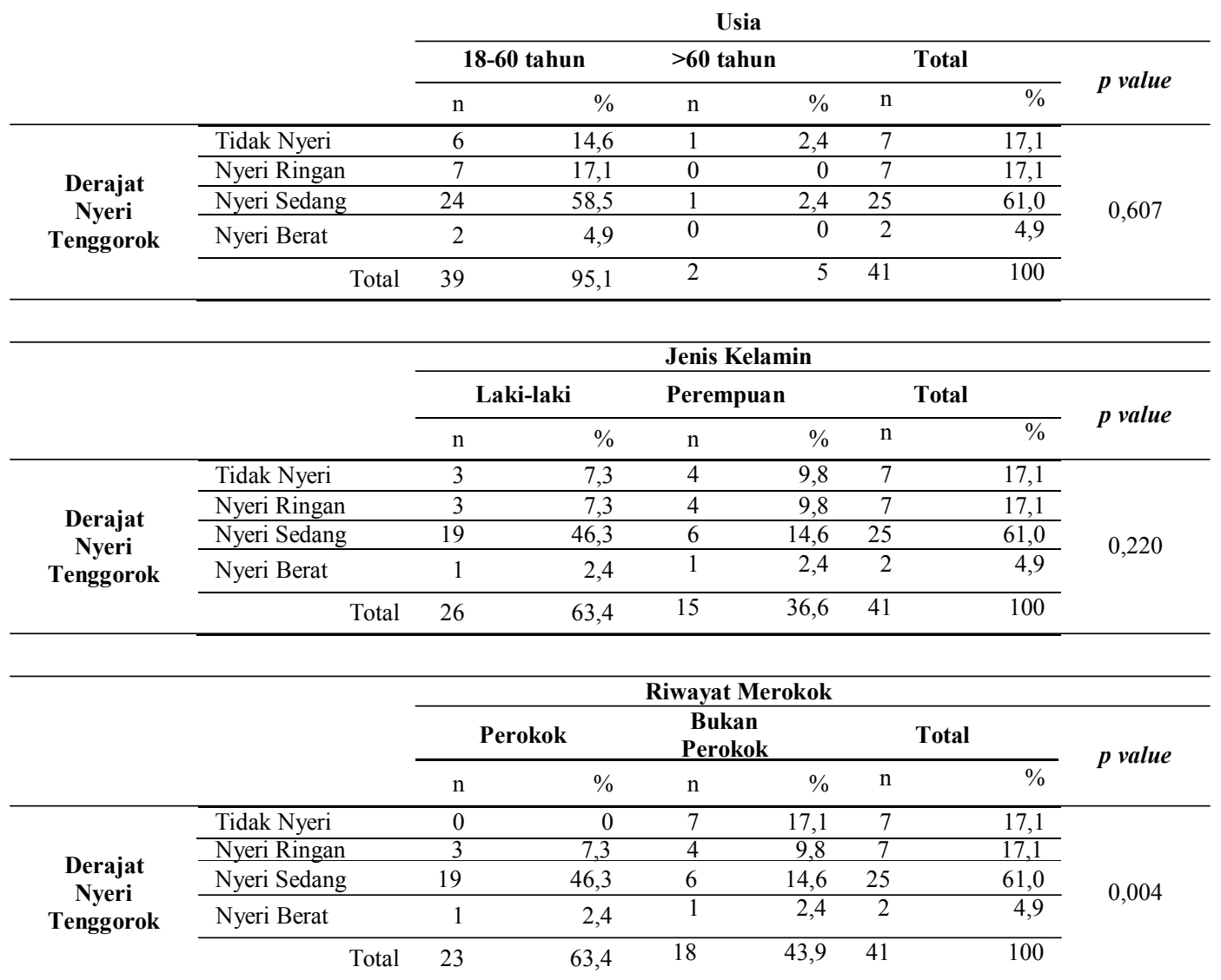

\begin{tabular}{|c|c|c|c|c|c|c|c|c|c|c|}
\hline & & \multicolumn{8}{|c|}{ Durasi Intubasi } & \multirow{3}{*}{ p value } \\
\hline & & \multicolumn{3}{|c|}{$\leq 60$ menit } & \multicolumn{3}{|c|}{$>60$ menit } & \multicolumn{2}{|c|}{ Total } & \\
\hline & & $\mathrm{n}$ & & $\%$ & $\mathrm{n}$ & & $\%$ & $\mathrm{n}$ & $\%$ & \\
\hline \multirow{8}{*}{$\begin{array}{c}\text { Derajat } \\
\text { Nyeri } \\
\text { Tenggorok }\end{array}$} & Tidak Nyeri & 5 & & 12,2 & 2 & & 4,9 & 7 & 17,1 & \multirow{5}{*}{0,011} \\
\hline & Nyeri Ringan & 6 & & 14,6 & 1 & & 2,4 & 7 & 17,1 & \\
\hline & Nyeri Sedang & 6 & & 14,6 & 19 & & 6,3 & 25 & 61,0 & \\
\hline & Nyeri Berat & 1 & & 2,4 & 1 & & 2,4 & 2 & 4,9 & \\
\hline & \multirow[t]{4}{*}{ Total } & 18 & & 43,9 & 23 & \multicolumn{2}{|c|}{56,1} & 41 & 100 & \\
\hline & & \multirow{2}{*}{\multicolumn{8}{|c|}{ Ukuran Pipa Endotrakeal }} & \\
\hline & & \multicolumn{2}{|c|}{ 6,5 ID } & \multicolumn{2}{|c|}{ 7,0 ID } & \multicolumn{2}{|c|}{ 7,5 ID } & Total & & \multirow{2}{*}{ p value } \\
\hline & & $\mathrm{n}$ & $\%$ & $\mathrm{n}$ & $\%$ & $\mathrm{n}$ & $\%$ & $\mathrm{n}$ & $\%$ & \\
\hline \multirow{5}{*}{$\begin{array}{c}\text { Derajat } \\
\text { Nyeri } \\
\text { Tenggorok }\end{array}$} & Tidak Nyeri & 1 & 2,4 & 6 & 14,6 & 0 & 0 & 7 & 17,1 & \multirow{5}{*}{0,002} \\
\hline & Nyeri Ringan & 6 & 14,6 & 1 & 2,4 & 0 & 0 & 7 & 17,1 & \\
\hline & Nyeri Sedang & 3 & 7,3 & 16 & 39,0 & 6 & 14,6 & 25 & 61,0 & \\
\hline & Nyeri Berat & 0 & 0 & 1 & 2,4 & 1 & 2,4 & 2 & 4,9 & \\
\hline & Total & 10 & 24,4 & 24 & 58,5 & 7 & 17,1 & 41 & 100 & \\
\hline
\end{tabular}




\section{PEMBAHASAN}

\section{Distribusi frekuensi derajat nyeri tenggorok pasien pasca operasi dengan anestesi umum intubasi endotrakeal}

Hasil dari analisis univariat menunjukkan bahwa responden yang mengalami nyeri tenggorok pasca operasi dengan anestesi umum intubasi endotrakeal di PPK BLUD RSU Cut Meutia Aceh Utara adalah derajat nyeri tenggorok sedang yaitu $61 \%(25 / 41)$. Hal ini ditandai dengan pengukuran nyeri menggunakan visual analogue score, dimana nilai 0 adalah tidak ada nyeri (VAS 0 ), nilai 1 adalah nyeri tenggorok ringan yaitu dijumpai nyeri tenggorok, rasa tidak nyaman, gatal ditenggorok namun tidak nyeri saat menelan (VAS 1-3), nilai 2 adalah nyeri tenggorok sedang yaitu dijumpai nyeri tenggorok dan nyeri saat menelan (VAS 4-6), nilai 3 adalah nyeri tenggorok berat yaitu dijumpai nyeri tenggorok disertai susah menelan atau tidak dapat menelan berada pada score 4-6 (16).

\section{Distribusi frekuensi faktor risiko pasien pasca operasi dengan anestesi umum intubasi endotrakeal}

Nyeri tenggorok sedang yang dikeluhkan pasien pasca operasi terjadi karena iritasi serta inflamasi lokal akibat trauma saat laringoskopi dan pemasangan pipa endotrakeal di daerah faring, laring, serta trakea. Kehilangan mukosa saluran napas atas serta laring pada keadaan lanjut akan mengakibatkan reaksi granulasi jaringan yang berlebihan serta menimbulkan granuloma (11). Hal ini juga dikarenakan terjadinya trauma pada struktur di sekitar jalan napas, misalnya pada tonsil, faring, laring, ataupun trakea. Tindakan intubasi endotrakeal dapat mengakibatkan inflamasi, edema, maupun ulserasi pada struktur tersebut. Trauma akibat intubasi endotrakeal ini biasanya akan pulih dengan sendirinya dan sering terjadi pada bagian tertentu pada jalan napas, seperti bagian posterior pita suara, medial aritenoid, posterior krikoid, dan juga anterior trakea. Keluhan nyeri tenggorok ini sering terjadi pada trauma mukosa trakea pasca intubasi endotrakeal (4).

Hasil dari analisis univariat menunjukkan bahwa responden yang mengalami nyeri tenggorok terbanyak adalah responden usia 18-60 tahun yaitu sebesar 95,1\% (39/41) dan yang paling sedikit adalah usia $>60$ tahun yaitu sebesar $4,9 \%(2 / 41)$. Hal ini dikarenakan responden usia 18-60 tahun lebih banyak melakukan kunjungan ke PPK BLUD RSU Cut Meutia Aceh Utara untuk menangani keluhan yang dirasakan dan mendapatkan tindakan operasi dengan anestesi umum intubasi endotrakeal dibandingkan dengan responden usia $>60$ tahun (Data Primer, 2018). Hal ini sesuai dengan penelitian yang dilakukan Gemechu, Gebremedhn dan Melkie (2017) yang menunjukkan responden yang mengalami nyeri tenggorok terbanyak adalah usia 18-60 tahun yaitu 58,6\%. Sedangkan rsponden nyeri tenggorok dengan usia $>60$ tahun yaitu $0,8 \%$ (5).

Penelitian yang dilakukan Biro, Seifert dan Pasch, (2005) dalam Fahriyani, Irawan dan Bebasari (2014) juga menemukan bahwa insidensi nyeri tenggorok pasca operasi dengan anestesi umum intubasi endotrakeal lebih tinggi pada kelompok usia yang lebih muda (1). Berdasarkan penelitian El-Boghdadly, Bailey dan Wiles (2016) hal ini dikarenakan usia muda merupakan salah satu faktor risiko 
yang menyebabkan kejadian nyeri tenggorok pasca operasi dengan anestesi umum intubasi endotrakeal (14).

Berdasarkan jenis kelamin responden yang mengalami nyeri tenggorok terbanyak adalah laki-laki yaitu sebesar $63,4 \%(26 / 41)$ dan responden perempuan yaitu sebesar $36,6 \%(15 / 41)$. Besarnya jumlah persentase nyeri tenggorok pada responden laki-laki dikarenakan sebagian besar responden laki-laki mempunyai faktor kebiasaan merokok dan tidak ditemukannya faktor kebiasaan merokok pada responden perempuan (Data Primer, 2018). Jenis kelamin merupakan salah satu faktor yang mempengaruhi terjadinya nyeri tenggorok pasca operasi dengan anestesi umum intubasi endotrakeal (17). Hal ini sejalan dengan penelitian Kadri et al. (2009) yang menyebutkan bahwa nyeri tenggorok pasca operasi dengan anestesi umum intubasi endotrakeal lebih banyak ditemukan pada responden laki-laki yaitu sebesar 92,9\%, sedangkan responden perempuan yang mengeluhkan nyeri tenggorok yaitu sebesar 78,6\%. Dari penelitian Paulauskienè dan Lesinskas (2012) yang meyebutkan bahwa frekuensi terjadinya nyeri tenggorok antara laki-laki dan perempuan adalah sama (1)(18).

Berdasarkan riwayat merokok responden yang mengalami nyeri tenggorok terbanyak adalah responden perokok yaitu sebesar 56,1\% (23/41), dan responden bukan perokok adalah sebesar 43,9\% (18/41) (Data Primer, 2018). Hal ini sesuai dengan penelitian Elhakim et al. (2000) yang menunjukkan bahwa responden perokok mengeluhkan nyeri tenggorok pasca intubasi yaitu sebesar $26 \%$, sedangkan kejadian nyeri tenggorok pasca intubasi pada responden bukan perokok yaitu sebesar $23 \%$ (19). Merokok meningkatkan risiko terjadinya komplikasi jalan nafas pada pasien akibat operasi (16). Responden perokok lebih berisiko mengalami nyeri tenggorok pasca operasi dengan anestesi umum intubasi endotrakeal. Hal ini dikarenakan kandungan zat iritan dalam rokok yang dapat memicu keringnya mukosa trakea dan penurunan integritas sel saluran pernapasan sehingga lebih rentan terhadap trauma (1).

Berdasarkan durasi intubasi responden yang mengalami nyeri tenggorok terbanyak adalah responden dengan durasi intubasi $>60$ menit yaitu sebesar $56,1 \%$ (23/41) dan pasien yang diintubasi $\leq 60$ menit yaitu sebesar 43,9\% (18/41). Hal ini dikarenakan sebagian besar responden mendapatkan tindakan operasi dengan durasi lama yaitu $>60$ menit sehingga durasi intubasi yang dilakukan pada pasien yaitu $>60$ menit yang mengakibatkan pasien lebih cenderung mengalami nyeri tenggorok (Data primer, 2018). Hal ini dikarenakan semakin lama durasi kontak mukosa saluran napas dengan pipa endotrakeal, semakin besar kemungkinan terjadinya trauma pada saluran nafas (14). Hal ini sesuai dengan penelitian yang dilakukan oleh Fahriyani, Irawan dan Bebasari (2014) yang menunjukkan responden terbanyak adalah pasien dengan durasi intubasi $>60$ menit yaitu sebesar $61,4 \%$, sedangkan responden dengan durasi intubasi $\leq 60$ menit yaitu sebesar $38,6 \%(1)$.

Berdasarkan ukuran pipa endotrakeal responden yang mengalami nyeri tenggorok terbanyak adalah pasien dengan menggunakan pipa endotrakeal ukuran 7,0 ID yaitu 58,5\% (24/41), sedangkan pasien yang menggunakan pipa endotrakeal 
ukuran 6,5 ID adalah 24,4\% (10/41), sebanyak 17,1\% (7/41) pasien yang menggunakan pipa endotrakeal ukuran 7,5 ID (Data Primer, 2018). Hal ini sesuai dengan penlitian yang dilakukan oleh Fahriyani, Irawan dan Bebasari (2014) yang menunjukkan responden terbanyak adalah pasien dengan menggunakan ukuran pipa endotrakeal 7,0 ID yaitu $58 \%$, sedangkan pasien dengan menggunakan ukuran pipa endotrakeal 6,5 ID yaitu $30,7 \%$ dan pasien dengan menggunakan ukuran pipa endotrakal 7,5 ID yaitu 11,3\% (1). Intubasi endotrakeal dapat dilakukan pada lakilaki dewasa menggunakan ukuran pipa 7,0 sampai 7,5 ID, sedangkan perempuan biasanya diintubasi dengan menggunakan ukuran pipa 7,0 sampai 8,0 ID dan ukuran pipa 7,5 ID dapat digunakan untuk hampir semua pasien (20).

\section{Hubungan nyeri tenggorok dan faktor risiko pasien pasca operasi dengan anestsi umum intubasi endotrakeal}

Data yang diperoleh dari hasil uji statistik menunjukkan bahwa tidak terdapat hubungan nyeri tenggorok dan usia pasien pasca operasi dengan anestesi umum intubasi endotrakeal di PPK BLUD RSU Cut Meutia Aceh Utara. Hasil ini sejalan dengan penelitian Eidi et al. (2014) yang menunjukkan bahwa tidak terdapat hubungan nyeri tenggorok dan usia pasien pasca operasi dengan anestesi umum intubasi endotrakeal Namun pada penelitian ini mengambil sampel umur 30-60 tahun. (21). Dalam penelitian Jaensson, Gupta dan Ulrica (2012) menyatakan bahwa alasan terjadinya nyeri tenggorok pada responden yang lebih tua adalah tidak jelas, namun dinyatakan bahwa pada perempuan kemungkinan terjadinya perubahan hormonal setelah menopause yang dapat menyebabkan kekeringan mukosa di saluran napas bagian atas, sehingga membuatnya lebih rentan terhadap cedera. Cedera pada epitelium seperti selama laringoskopi dan intubasi lebih lanjut dapat merusak mukosa kering dan dengan demikian menyebabkan terjadinya komplikasi pasca operasi. Hal ini dapat didukung oleh fakta bahwa penggunaan laringoskop pada lapisan mukosa juga merupakan faktor risiko yang signifikan dalam terjadinya nyeri tenggorok dalam penelitian saat ini. Penggunaan laringoskop meningkatkan risiko terjadinya nyeri tenggorok sebanyak lebih dari 3 kali (23).

Faktor-faktor yang dapat mempengaruhi nyeri tenggorok dan usia pasien pasca operasi dengan anestesi umum intubasi endotrakeal dapat mempengaruhi hasil penelitian. Keterbatasan penelitian ini adalah responden usia $>60$ tahun didapatkan hanya sedikit yaitu 4,9\% (2/41) dari yang memenuhi kriteria inklusi dan responden usia 18-60 tahun lebih banyak melakukan kunjungan ke PPK BLUD RSU Cut Meutia Aceh Utara untuk menangani keluhan yang dirasakan dan mendapatkan tindakan operasi dengan anestesi umum intubasi endotrakeal dibandingkan dengan responden usia $>60$ tahun. Rendahnya kunjungan pada usia $>60$ tahun ke rumah sakit untuk menangani penyakitnya disebabkan oleh beberapa faktor, salah satunya adalah keluarga. Selain itu, faktor lainnya yang mempengaruhi kunjungan usia tua ke rumah sakit adalah psikis, fisiologis, biologis dan sosioekonomi. Hal ini dikarenakan pada umur yang semakin tua maka tingkat ketergantungan terhadap orang lain semakin tinggi. (24). Hubungan Nyeri Tenggorok dan Jenis Kelamin Pasien Pasca Operasi dengan Anestesi Umum Intubasi Endotrakeal di PPK BLUD RSU Cut Meutia Aceh Utara Data yang diperoleh dari hasil uji statistik menunjukkan bahwa tidak Jurnal Averrous Vol.4 No.2 2018 
terdapat hubungan nyeri tenggorok dan jenis kelamin pasien pasca operasi dengan anestesi umum intubasi endotrakeal di PPK BLUD RSU Cut Meutia Aceh Utara. Hasil ini sejalan dengan penelitian Eidi et al. (2014) yang menunjukkan bahwa tidak terdapat hubungan nyeri tenggorok dan jenis kelamin pasien pasca operasi dengan anestesi umum intubasi endotrakeal (21). Hal ini juga sesuai dengan penelitian Jaensson, Gupta dan Ulrica (2012) yang menyebutkan bahwa tidak ada bukti yang jelas tentang perempuan lebih berisiko untuk mengalami nyeri tenggorok pasca operasi dengan anestesi umum intubasi endotrakeal (23).

Hal ini disebabkan oleh adanya beberapa faktor yang mempengaruhi terjadinya nyeri tenggorok pasien pasca operasi dengan anestesi umum intubasi endotrakeal, sedangkan jenis kelamin merupakan salah satu faktor yang mempengaruhi terjadinya nyeri tenggorok tersebut (17). Adanya masalah kesenjangan laki-laki dan perempuan dalam hal akses, partisipasi, kontrol, dan manfaat yang diperoleh dalam upaya pelayanan kesehatan yang menyebabkan ketidaksetaraan terhadap status kesehatan laki-laki dan perempuan (25). Adanya perbedaan anatomi laring antara laki-laki dan perempuan (23) dimana pada pria panjang laring sekitar $45 \mathrm{~mm}$ dan memiliki diameter sekitar $35 \mathrm{~mm}$, sedangkan pada wanita memiliki panjang sekitar $35 \mathrm{~mm}$ dan berdiameter sekitar $25 \mathrm{~mm}$ (26) dan lapisan mukosa pada perempuan lebih tipis sehingga lebih mudah mengalami edema (16).

Siklus menstruasi pada perempuan mempengaruhi rasa disertai oleh banyak fluktuasi hormonal. Pada fase folikular, kadar estrogen dan FSH meningkat, terjadinya peningkatan LH secara tiba-tiba selama ovulasi dan pada fase luteal, preferensi progesteron diamati. Fluktuasi hormonal ini dapat mempengaruhi kualitas hidup pada beberapa perempuan dan mewakili perubahan suasana hati dan emosi yang disebut sindrom pramenstruasi (PMS), tetapi perubahan tersebut dapat mempengaruhi ambang toleransi rasa sakit. Studi pada manusia menunjukkan peningkatan kepekaan terhadap rasa sakit selama fase luteal untuk rangsangan yang paling menyakitkan kecuali rangsangan listrik. Selain itu, respons terhadap analgesik opioid dan nonopioid berbeda pada perempuan dan mereka membutuhkan dosis yang relatif lebih tinggi dibandingkan pria (27).

Responden yang didapatkan sebagian besar yaitu jenis kelamin laki-laki adalah perokok, sedangkan semua responden jenis kelamin perempuan adalah bukan perokok. Responden perokok yang menjalani operasi dengan anestesi umum intubasi endotrakeal mempunyai resiko yang cukup besar berkaitan dengan efektifitas jalan nafas sehubungan produksi mukus yang berlebihan, batuk, spasme bronkhus dan sesak akibat dari radang saluran nafas (28). Hal ini sejalan dengan penelitian yang dilakukan Saptawati et al. (2012) yang menyebutkan bahwa faktor kebiasaan merokok juga dapat meningkatkan risiko infeksi saluran pernapasan pasien. Merokok menyebabkan beberapa patofisiologi berubah di sistem pernapasan termasuk sistem kekebalan tubuh dan menurunkan kemampuan untuk membersihkan patogen yang terinhalasi (29).

Data yang diperoleh dari hasil uji statistik menunjukkan bahwa terdapat hubungan nyeri tenggorok dan riwayat merokok pasien pasca operasi dengan anestesi umum intubasi endotrakeal di PPK BLUD RSU Cut Meutia Aceh Utara. Hasil ini sejalan dengan penelitian Biro, Seifert dan Pasch (2005) dan Canbay et al. (2008) yang menunjukkan bahwa terdapat hubungan nyeri teggorok dan riwayat 
merokok pasien pasca operasi dengan anstesi umum intubasi endotrakeal. Merokok tetap menjadi salah satu faktor risiko paling umum yang memengaruhi pasien untuk mengalami komplikasi perioperatif. Insidensi nyeri tenggorok pada pasien perokok pasca operasi dengan anestesi umum intubasi endotrakeal enam kali lebih tinggi dibandingkan dengan pasien yang bukan perokok (16).

Secara patologis fase gas rokok berhubungan dengan hiperplasia kelenjar mukus dan metaplasia skamuosa epitel saluran pernafasan (28). Perokok kronis meyebabkan peradangan epitel laring, metaplasia, dan displasia, yang dapat merusak integritas laringeal dan fungsi. Merokok mempengaruhi berbagai organ, seperti jantung, paru-paru, kekebalan tubuh dan sistem saraf sedangkan sistem pernapasan adalah yang paling sering terkena selama periode perioperatif. Anestesi umum intubasi endotrakeal dapat berkontribusi dalam memperburuk komplikasi pernapasan. Merokok menginduksi perubahan kronis pada epitel saluran napas bagian atas, terdapat paparan reseptor saluran napas subepitelial yang lebih besar terhadap rangsangan. Intubasi endotrakeal menghasilkan peregangan stimulus di trakea yang disebabkan oleh tabung dan mansetnya (31).

Rokok mengandung bahan kimia seperti benzena, formaldehida, ammonia, aseton, tar, nikotin, karbon monoksida, arsen, hidrogen sianida, cadmium dan metanol yang dihisap sebagian besar mempengaruhi kesehatan (28). Merokok adalah risiko yang dapat dimodifikasi untuk komplikasi pernapasan perioperatif sekunder untuk peningkatan sensitivitas refluks saluran napas bagian atas karena zat yang dihirup selama merokok. Telah diamati bahwa perokok lebih rentan terhadap terjadinya komplikasi pada periode pasca operasi. Ini mungkin dikaitkan dengan peradangan epitel laring, metaplasia, atau displasia karena iritasi kronis oleh zat-zat dalam asap rokok sehingga merusak integritas laring dan paparan reseptor saluran napas subepitel untuk stimulasi (32).

Data yang diperoleh dari hasil uji statistik menunjukkan bahwa terdapat hubungan nyeri tenggorok dan durasi intubasi pasien pasca operasi dengan anestesi umum intubasi endotrakeal di PPK BLUD RSU Cut Meutia Aceh Utara. Penelitian Edomwonyi et al., (2006) menunjukkan bahwa terdapat hubungan nyeri tenggorok dan durasi intubasi pasien pasca operasi dengan anestesi umum intubasi endotrakeal, dimana durasi intubasi lebih dari 60 menit berkontribusi pada insiden komplikasi tenggorokan yang lebih tinggi. Hal ini disebabkan oleh lamanya kontak mukosa saluran napas dengan pipa endotrakeal sehingga menyebabkan terjadinya trauma pada mukosa saluran napas dan perfusi jaringan. Gangguan perfusi jaringan dapat terjadi karena adanya penekanan cuff pada mukosa trakea. Tekanan cuff yang melebihi tekanan kapiler trakea $\left(27-40 \mathrm{cmH}_{2} \mathrm{O}\right)$ selama minimal 15 menit akan menimbulkan iskemia jaringan (1).

Data yang diperoleh dari hasil uji statistik menunjukkan bahwa terdapat hubungan nyeri tenggorok dan ukuran pipa endotrakeal pasien pasca operasi dengan anestesi umum intubasi endotrakeal di PPK BLUD RSU Cut Meutia Aceh Utara. Hal ini sejalan dengan penlitian yang dilakukan oleh Jaensson, Gupta dan Ulrica (2012) yang menunjukkan bahwa terdapat hubungan nyeri tenggorok dan ukuran pipa endotrakeal pasien pasca operasi dengan anestesi umum intubasi 
endotrakeal. Intubasi endotrakeal dapat dilakukan pada laki-laki dewasa menggunakan ukuran pipa 7,0 sampai 7,5 ID, sedangkan wanita biasanya diintubasi dengan menggunakan ukuran pipa 7,0 sampai 8,0 ID dan ukuran pipa 7,5 ID dapat digunakan untuk hampir semua pasien(23)(20). Hal ini sejalan dengan penelitian Inoue et al. (2015) yang menunjukkan bahwa terdapat hubungan nyeri tenggorok dan ukuran pipa endotrakeal pasien pasca operasi dengan anestesi umum intubasi endotrakeal di PPK BLUD RSU Cut Meutia Aceh Utara. Dalam penelitian ini menunjukkan bahwa responden laki-laki diintubasi dengan menggunakan ukuran pipa endotrakeal yaitu 8,0 ID dan responden wanita menggunakan ukuran pipa endotrakeal 7,0 $\mathrm{ID}(33)$. Berdasarkan penelitian yang dilakukan oleh $\mathrm{Hu}$ et al. (2013) menunjukkan bahwa responden wanita menggunakan ukuran pipa endotrakeal 6,0 ID (13).

Ukuran pipa endotrakeal menjadi peran penting dalam terjadinya nyeri tenggorok pasca operasi dengan anestesi umum intunbasi endotrakeal, dimana risiko terjadinya nyeri tenggorok meningkat hampir 3 kali lipat dibandingkan jika menggunakan ukuran pipa endotrakeal yang lebih kecil. Penggunaan ukuran pipa endotrakeal 7,0 ID mungkin tidak cocok pada responden perempuan dikarenakan laring wanita yang berukuran sempit dan disarankan bahwa penggunaan ukuran pipa endotrakeal untuk laki-laki dan perempuan harus dikurangi untuk meminimalkan kerusakan pada cincin krikoid (22). Hal ini dikarenakan penggunaan pipa endotrakeal dengan ukuran yang lebih besar berpotensi untuk menimbulkan nyeri tenggorok terkait dengan semakin luasnya area kontak antara pipa endotrakeal dengan mukosa saluran napas (1).

\section{Kesimpulan}

Kesimpulan hasil penelitian ini adalah:

1. Pasien pasca operasi dengan anestesi umum intubasi endotrakeal di PPK BLUD RSU Cut Meutia Aceh Utara paling banyak mengeluhkan nyeri tenggorok derajat sedang (nyeri tenggorok dan nyeri pada saat menelan).

2. Faktor risiko kejadian nyeri tenggorok pasien pasca operasi dengan anestesi umum intubasi endotrakeal adalah pasien usia 18-60 tahun, jenis kelamin laki-laki, perokok, dengan durasi intubasi $>60$ menit, dan ukuran pipa endotrakeal 7,0 ID.

3. Adanya hubungan nyeri tenggorok dengan riwayat merokok, durasi intubasi dan ukuran pipa endotrakeal serta tidak terdapat hubungan nyeri tenggorok dengan usia dan jenis kelamin. 


\section{DAFTAR PUSTAKA}

1. Fahriyani F, Irawan D, Bebasari E. Gambaran Kejadian Nyeri Tenggorok dan Serak pada Pasien yang Menjalani Anestesi Umum Endotrakeal di RSUD Arifin Achmad Pekanbaru. J Ilmu Kedokt. 2014;8(2):91-100.

2. Priyonggo R, Suwarman, Nawawi AM. Pemberian Strepsils Sebagai Lozenge Praoperasi untuk Mengurangi Nyeri Tenggorok Pascaintubasi pipa Endotrakeal. Jurna Anestesi Perioper. 2014;2(3):213-21.

3. Lee JY, Sim WS, Kim ES, Lee SM, Kim DK, Na YR, et al. Incidence and Risk Factors of Postoperative Sore Throat After Endotracheal Intubation in Korean Patients. J Int Med Res. 2017;45(2):744-52.

4. Wijaya AA, Garditya R, Marsaban AHM, Heriwardito A, Anestesiologi D. Perbandingan Penggunaan Triamsinolon Asetonid Topikal dengan Deksametason Intravena dalam Mengurangi Insidens Nyeri Tenggorok Pascabedah. J Anestesi Perioper. 2015;3(71):117-22.

5. Gemechu BM, Gebremedhn EG, Melkie TB. Risk Factors for Postoperative Throat Pain After General Anaesthesia with Endotracheal Intubation at The University of Gondar Teaching hospital, Northwest Ethiopia, 2014. Pan Afr Med J. 2017;27:1-9.

6. Firza TA, Umar N, Ihsan M. Perbandingan Obat Kumur Benzydamine Hydrochloride 22,5 mg dan Ketamin $40 \mathrm{mg}$ dalam Mengurangi Nyeri Tenggorok dan Suara Serak Akibat Intubasi Endotrakeal. J Anestesi Perioper. 2017;5(1):57-66.

7. Sally R, Widyastuti Y, Widodo U. Perbandingan Kejadian Nyeri Tenggorok Paska Ekstubasi Akibat Penggunaan Pipa Endotrakeal. J Komplikasi Anastesi. 2014;1(2):15-24.

8. Erikson, Suryani E. Hubungan Respon Nyeri Tenggorokan pada Pemberian Xilocain Spray Pasca Pemasangan Endotrakheal Tube Menurut Karakteristik Paien di RSUD Sleman. Dep Nurs Polytech Kemenkes Yogyakarta. 2014;3(3):16-22.

9. Handady SO, Elsir Y, Sanhouri M, Mimoun H, Alawad AAM. The Effect of Beatamethasone Gel in Reducing Post Operative Sore Throat and Cough After Endotracheal Intubation in Khartoum Teaching Hospital in Sudan. Open Sci J Clin Med. 2015;3(4):140-4.

10. Hagberg C, Krier C. Complications of Managing The Airway. Best Pract Res Clin Anesthesiol. 2005;19(4):641-59. 
11. Satriyanto MD, Husaeni H, Wargahadibrata AH. Ketamin Kumur untuk Mengurangi Sore Throat Pascaintubasi. Jurna Anestesi Perioper. 2014;2(1):63-72.

12. Muhamad M, Fuadi I, Nawawi AM. Perbandingan Penggunaan Topikal Spray Benzidamin $\mathrm{HCl}$ 0, 15\% dan Gel Lidokain 2\% pada Pipa Endotrakeal terhadap Kejadian Nyeri Tenggorok Pascaintubasi Endotrakeal. J Anastesi Perioper. 2015;3(1):123-30.

13. Hu B, Bao R, Wang X, Liu S. The Size of Endotracheal Tube and Sore Throat after Surgery: A Systematic Review and Meta-Analysis. PLoS One. 2013;8(10):74467.

14. El-Boghdadly K, Bailey CR, Wiles MD. Postoperative Sore Throat: A Systematic Review. Anaesthesia. 2016;71(6):706-17.

15. Biro P, Seifert B, Pasch T. Complaints of sore throat after tracheal intubation: a prospective evaluation. Eur J Anaesthesiol. 2005;22(4):307-11.

16. Kulsum. Perbandingan Keberhasilan Obat Kumur Ketamin dan Aspirin dalam Mencegah Nyeri Tenggorok dan Suara Serak Akibat Intubasi Endotrakeal. tesis. 2012;

17. Quinn AC, Milne D, Columb M, Gorton H, Knight M. Failed Tracheal Intubation in Obstetric Anaesthesia: 2 yr National Case-Control Study in The UK. Br J Anaesth. 2013;110(1):74-80.

18. Paulauskienè I, Lesinskas E. Laryngopharyngeal complaints following short-term endotracheal intubation: peculiarities of males and females. Acta Medica Litu. 2012;19(2):51-7.

19. Edomwonyi NP, Ekwere IT, Omo E, Rupasinghe A. Postoperative Throat Complications after Tracheal Intubation. Ann Afr Med. 2006;5(1):28-32.

20. R J, Roberts, R J, Hedges. Tracheal Intubation. In: Clinical Procedures in Emergency Medicine. 2013. p. 62-102.

21. Eidi M, Toutounchi SJS, Kolahduzan K, Sadeghian P, Toutounchi NS. Comparing the Effect of Dexamethasone before and after Tracheal Intubation on Sore Throat after Tympanoplasty Surgery: A Randomized Controlled tria. Iran J Otorhinolaryngol. 2014;26(75):89-98.

22. Jaensson M, Gupta A, Ulrica. Risk Factors for Development of Postoperative Sore Throat and Hoarseness After Endotracheal Intubation in Women: A Secondary Analysis. AANA J. 2012;80(4):67-73.

23. Harahap YS, Tavianto D, Surahman E. Perbandingan Angka Keberhasilan Pemasangan Laryngeal Mask Airway (LMA) Jenis Klasik pada Usaha Pertama antara Teknik Balon Dikempiskan dan Dikembangkan Sebagian 
pada Pasien Dewasa. J Anestesi Perioper. 2016;4(1):30-5.

24. Lestari P, Hadisaputro S, Pranarka K. Beberapa Faktor yang Berperan Terhadap Keaktifan Kunjungan Lansia ke Posyandu Studi Kasus di Desa Tamantirto Kecamatan Kasihan Kabupaten Bantul Propinsi DIY. Media Med Indones. 2011;45(2):74-82.

25. Widihastuti A. Gender. 2013. p. 1-6.

26. Hutama RM. Pengaruh Durasi Tindakan Intubasi Terhadap Rate Pressure Product (RPP). 2014. p. 6-18.

27. Orandi A, Orandi A, Soleimani ANFHS, Zahabi S. Post-Intubation Sore Throat and Menstruation Cycles. Anesth Pain Med. 2013;3(2):243-9.

28. Amon D. Perbedaan Keefektifan Jalan Nafas Pasien Perokok dan Bukan Perokok Pasca Operasi di Rumah Sakit At-Turots Al-Islamy Yogyakarta. 2013. p. 1-4.

29. Clinical vs. bispectral index-guided propofol induction of anesthesia: A comparative study [Internet]. Vol. 7, Saudi Journal of Anaesthesia. 2013. p. 75 .

30. Canbay O, Celebi N, Sahin A, Celiker V, Ozgen S, Aypar U. Ketamine Gargle for Attenuating Postoperative Sore Throat. $\mathrm{Br} \mathrm{J}$ Anaesth. 2008;100(4):490-3.

31. Camacho Navarro LH, Moreira e Lima R, Simões Aguiar A, Cerqueira Braz JR, Carness JM, Pinheiro Módolo NS. The effect of intracuff alkalinized 2\% lidocaine on emergence coughing, sore throat, and hoarseness in smokers. Rev Assoc Med Bras. 2012;58(2):248-53.

32. Gupta D, Agrawal S, Sharma JP. Evaluation of preoperative Strepsils lozenges on incidence of postextubation cough and sore throat in smokers undergoing anesthesia with endotracheal intubation. Saudi J Anaesth. 2014;8(2):244-8.

33. Inoue S, Abe R, Tanaka Y, Kawaguchi M. Tracheal Intubation by Trainees does not Alter The Incidence or Duration of Postoperative Sore Throat and Hoarseness: A Teaching Hospital-Based Propensity Score Analysis. Br J Anaesth. 2015;115(3):463-9. 